\title{
A small RNA serving both the Hfq and CsrA regulons
}

\author{
Erik Holmqvist and Jörg Vogel ${ }^{1}$ \\ Institute for Molecular Infection Biology, University of Würzburg, D-97080 Würzburg, Germany
}

The abundant RNA-binding proteins CsrA and Hfq each impact bacterial physiology by working in conjunction with small RNAs to control large post-transcriptional regulons. The small RNAs involved were considered mechanistically distinct, regulating mRNAs either directly through Hfq-mediated base-pairing or indirectly by sequestering the global translational repressor CsrA. In this issue of Genes \& Development, Jørgensen and colleagues (pp. 1132-1145) blur these distinctions with a dualmechanism small RNA that acts through both Hfq and CsrA to regulate the formation of bacterial biofilms.

Bacteria express large numbers of small RNAs (sRNAs), the vast majority of which function as regulators of gene expression by targeting either mRNAs directly or cellular proteins involved in gene transcription or translation (Storz et al. 2011). A typical bacterium may encode $>100$ different sRNAs, which, when normalized to the number of protein-coding genes, rivals the output of regulatory sRNAs in animals and plants.

However, unlike in eukaryotes, where, for example, microRNAs are characterized by their uniform length and processing pathway, the sheer heterogeneity in length and structure has made the bacterial sRNAs less amenable to easy categorization: Most of them are between 50 and 300 nucleotides (nt) long and possess stem-loop structures as well as unstructured regions. In other words, sequence alone usually reveals little if anything as to the function of a newly discovered sRNA. Despite the lack of uniform classes, some common principles of post-transcriptional control by these bacterial sRNAs exist (Storz et al. 2011). Very prominent examples include the mechanistically distinct sRNAs that associate with either Hfq or CsrA, two abundant RNA-binding proteins that are nearly ubiquitous in bacteria.

\section{sRNAs, Hfq, and CsrA}

Hfq-associated sRNAs constitute the largest class of post-transcriptional regulators known in bacteria to date

[Keywords: Hfq; CsrA; CsrB; PGA; c-di-GMP]

${ }^{1}$ Corresponding author

E-mail joerg.vogel@uni-wuerzburg.de

Article is online at http://www.genesdev.org/cgi/doi/10.1101/gad.220178.113.
(Vogel and Luisi 2011). Similar to eukaryotic microRNAs, they use short seed pairing to interact with mRNAs, resulting in repression or even activation of a target gene at the levels of translation, mRNA stability, or both. One sRNA typically controls a regulon containing multiple mRNAs in a manner similar to transcription factors that recognize multiple promoters in a genome. The primary role of $\mathrm{Hfq}$ in this regulation is that of a molecular matchmaker; i.e., the protein may simultaneously bind sRNA and mRNA to facilitate a productive base-pairing interaction. Hfq also has additional functions; it protects the sRNAs from degradation prior to target pairing and can also recruit auxiliary factors for target regulation, such as the major ribonuclease RNase E (Morita and Aiba 2011). Much of our knowledge of Hfq-associated sRNAs stems from work in Escherichia coli and Salmonella, where RNA pull-down experiments suggest that up to $25 \%$ of all mRNAs may be subject to this type of posttranscriptional control (Chao et al. 2012; Zhang et al. 2013). There is an ever-growing list of biological processes and stress responses in which Hfq and sRNAs participate, as demonstrated by the recent work on phosphosugar detoxification (Rice et al. 2012; Papenfort et al. 2013), catabolite repression (Beisel et al. 2012), envelope stress (Gogol et al. 2011), metal homeostasis (Desnoyers and Masse 2012; Coornaert et al. 2013), and virulence (Koo et al. 2011), to mention just a few.

Likewise, post-transcriptional regulation by CsrA and sRNAs affects many pathways. Originally discovered as a regulator of carbon starvation and glycogen biosynthesis in E. coli (Romeo et al. 1993), the CsrA protein is now also known to play a prominent role in the physiology and virulence of numerous pathogenic bacteria (Heroven et al. 2012; Romeo et al. 2013). In contrast to Hfq's rather passive matchmaker role in mRNA regulation by sRNAs, CsrA takes the driver's seat and represses protein synthesis directly by binding to the $5^{\prime}$ regions of mRNAs. Similar to the scope of Hfq-based regulation, microarray and RNA pull-down data hint at a large post-transcriptional regulon whereby CsrA impacts $>20 \%$ of all mRNAs (Lawhon et al. 2003; Edwards et al. 2011). However, the role of the CsrA-associated sRNAs is very different from those that associate with Hfq: Instead of directly regulating specific mRNAs, they act as antagonistic RNA sponges of CsrA. For example, the prototypical CsrB sRNA of E. coli contains 18 GGA motifs in hairpin regions that mimic 
multiple binding sites of CsrA in mRNAs (Romeo et al. 2013). E. coli was known to express two RNA sponges of CsrA (i.e., the CsrB and CsrC sRNAs) (Romeo et al. 2013); other bacteria, such as Vibrio or Pseudomonas species, possess even more sponge RNAs to regulate complex behaviors such as quorum sensing and motility through CsrA or its homolog, RsmA (Lenz et al. 2005; Brencic and Lory 2009).

According to coimmunoprecipitation experiments (Zhang et al. 2003; Sittka et al. 2008), the CsrB and CsrC sRNAs do not interact with Hfa, and although CsrA can repress the synthesis of Hfq in vivo (Baker et al. 2007), the two proteins and their sRNAs were assumed to run separate molecular operations. In this issue of Genes \& Development, Jørgensen et al. (2013) present an unexpected twist to the story by revealing that the 90-nt sRNA McaS (Fig. 1) acts by both direct Hfq-dependent base-pairing with mRNAs and indirect mRNA control via CsrA sequestration to regulate biofilm formation in $E$. coli.

\section{Biofilm regulation by sRNAs}

Biofilm formation is a sessile bacterial lifestyle of high medical relevance in which free-growing bacteria become immobile and form clusters of cells, often containing different bacterial species, to protect themselves from harsh conditions, including antibiotic treatment (Flemming and Wingender 2010; Lopez et al. 2010). The genetic programs that decide between motility and biofilm are subject to tight control on both the transcriptional and post-transcriptional levels. This includes the regulation of CsgD, a transcriptional activator of genes required for the synthesis of curli and cellulose, which are important for formation of the biofilm matrix (Povolotsky and Hengge 2012). More than 10 transcription factors, each responding to different signals, control the $\operatorname{csg} D$ gene (Ogasawara et al. 2010).
In addition, more recent studies have identified five Hfq-associated sRNAs, again from different regulons, that target the $5^{\prime}$ untranslated region (UTR) of $\operatorname{csg} D$ mRNA; one of them is McaS (Jørgensen et al. 2012; Thomason et al. 2012). McaS was shown to inhibit translation initiation of the $\operatorname{csg} D$ mRNA by Hfq-dependent base-pairing with a conserved region that turned out a hot spot for sRNA action (Holmqvist et al. 2010, 2013; Jørgensen et al. 2012; Mika et al. 2012; Thomason et al. 2012). Although their individual importance in the regulation of CsgD synthesis is not yet clear, the combined activities of these sRNAs restricts the expression of curli adhesins via the repression of CsgD. The McaS sRNA may be very important in the decision-making process for or against biofilm because it also regulates the opposite motility arm through activating translation of the $\mathrm{FlhD}_{2} \mathrm{C}_{2}$ master regulator of flagellar synthesis, again by Hfq-dependent mRNA pairing. Similar to $\mathrm{CsgD}, \mathrm{FlhD}_{2} \mathrm{C}_{2}$ is also regulated post-transcriptionally by multiple sRNAs (De Lay and Gottesman 2012; Thomason et al. 2012).

Given that McaS controls two important biofilm and motility functions, a further observation by Thomason et al. (2012) that it also activated PgaA production should have come as no surprise. The PgaA protein is required for production of the biofilm-promoting adhesin PGA (poly3-1,6-N-acetyl-d-glucosamine) (Wang et al. 2004), which forms a biofilm distinct from the one mediated by the curli pathway. However, while identifying the base-pairing interactions underlying $\operatorname{csg} D$ and $f 1 h D C$ mRNA regulation proved straightforward, how McaS recognized the pgaA mRNA remained nebulous (Thomason et al. 2012); that is, regulation was abolished by point mutations in McaS regions predicted to base-pair with the pgaA 5' UTR. However, a rescue through compensatory base substitution in pgaA-the gold standard in target validation-was not successful (Thomason et al. 2012), and this is where the present story begins.

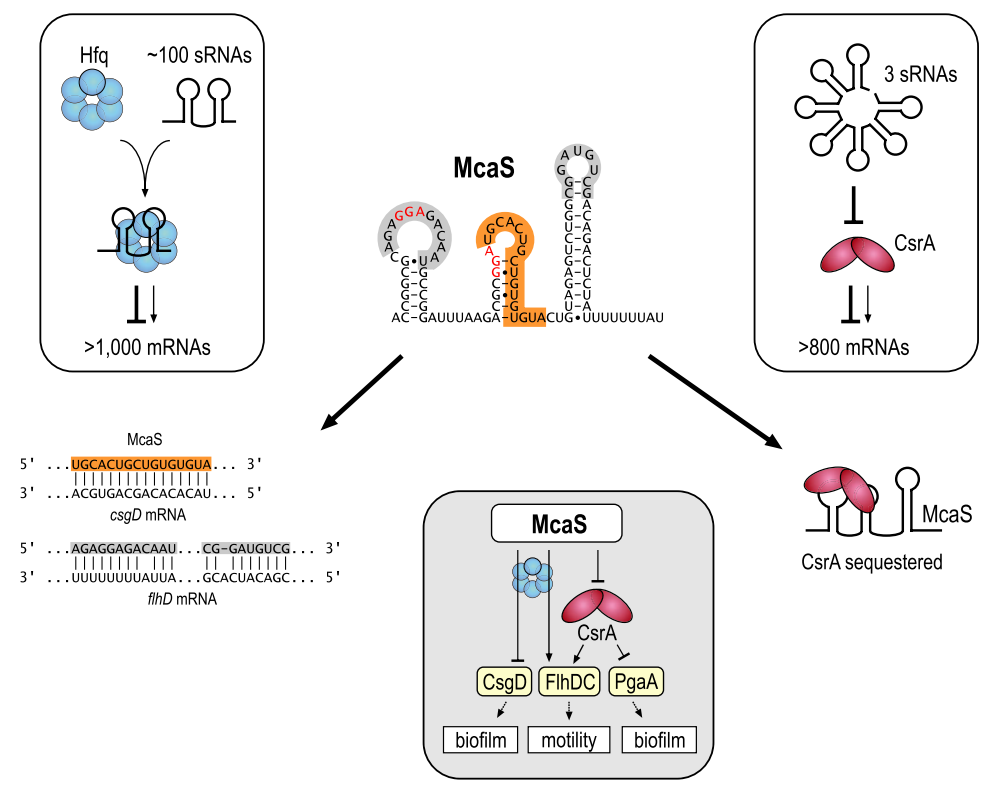

Figure 1. McaS acts in both the Hfq and CsrA regulons. Many small RNAs associate with the hemaxeric RNA-binding protein Hfq to regulate mRNAs through base-pairing (top left), whereas others act to sequester the RNA-binding protein CsrA to modulate its impact on mRNAs (top right). Positive regulation is indicated by arrows, and negative regulation is indicated by lines with blunt ends. The sequence and secondary structure of McaS sRNA, the base-pairing interactions between McaS and the $\operatorname{csg} D$ and $f 1 h D$ mRNAs, or the alternative interaction between McaS and CsrA are shown. Colorcoding in the McaS sequence is as follows: GGA motifs that interact with CsrA are in red, nucleotides that interact with $\operatorname{csg} D$ are highlighted with orange, and nucleotides that interact with $f 1 h D$ are highlighted with gray. Shown below are the regulatory relationships between McaS and genes involved in motility and two different forms of biofilm. See the text for references. 


\section{A sRNA of the Hfq class acts as a CsrA decoy}

Not only Hfq but also CsrA impact motility and biofilm formation. For example, CsrA promotes motility through the activation of $\mathrm{FlhD}_{2} \mathrm{C}_{2}$ synthesis (Wei et al. 2001; Yakhnin et al. 2013) while also inhibiting biofilm formation by down-regulating diguanylate cyclases that synthesize the second messenger c-di-GMP $\left[\right.$ bis- $\left(3^{\prime}-5^{\prime}\right)$-cyclicdimeric guanosine monophosphate] (Jonas et al. 2008). Strikingly, CsrA was also known to directly repress translation of the pgaA mRNA by binding to its Shine-Dalgarno sequence (Wang et al. 2005). Could it be that McaS-rather than by direct base-pairing-acted as a decoy of CsrA, loosening the protein's grip on the pgaA mRNA and thereby indirectly promoting the production of the PGA adhesin?

In their study, Jørgensen et al. (2013) present several lines of evidence for such a novel mechanistic link between the CsrA and Hfq regulons. They show that McaS-mediated activation of a minimal pgaA reporter fusion requires the presence of CsrA, while the much truncated pgaA 5' UTR sequence in this minimal reporter is devoid of potential sites for stable base-pairing with the McaS sRNA. Inspection of the McaS sequence reveals several GGA motifs that partially or entirely reside in loops of hairpin structures, reminiscent of known CsrA-binding sites. Mutations in two of these GGA motifs prevent McaS-dependent activation of $\mathrm{pgaA}$. In support of a stable RNA-protein interaction, McaS can be immunoprecipitated with CsrA in E. coli cell lysates and binds the protein with nanomolar affinity in vitro. Furthermore, McaS impacts other CsrA-controlled genes, and this effect is dependent on the GGA motifs in McaS. Thus, gene regulation by McaS through CsrA is a broader phenomenon and not restricted to pgaA. Phenotypically, the McaS-dependent activation of PgaA expression is shown to result in increased synthesis and export of the PGA adhesin, while biofilm assays clearly establish McaS as an important regulator of PGA-dependent biofilms. Intriguingly, under the conditions tested, biofilm formation was dependent on McaS but not on CsrB, suggesting that these CsrA sponges act in a nonredundant fashion during bacterial growth. In part, this may be explained by the different accumulation patterns of CsrB, CsrC, and McaS, with McaS being the most prevalent in the biofilmpromoting late stationary phase of growth. Taken together, McaS is the first example of a sRNA that regulates gene expression through both CsrA and Hfq.

The elegance of this novel RNA link notwithstanding, the present findings invite further research into both the physiology and the molecular mechanism of McaS-mediated regulation. As previously stated, the commitment to biofilm formation is an exceptionally tightly controlled process, with many different players intertwined through coherent and incoherent regulatory loops whose overall functions appear to ensure that the metabolically costly transition from motility to sessility occurs in a switchlike, nongradient fashion (Povolotsky and Hengge 2012). Even with that in mind, why McaS concomitantly activates both adhesin production $(\mathrm{pgaA})$ and motility $(\mathrm{flhDC})$ remains to be fully understood. Both McaS and CsrA activate the flhDC mRNA, although by different mechanisms, but since McaS also sequesters CsrA, the net result of this incoherent feed-forward loop may even be reduced synthesis of $\mathrm{FlhD}_{2} \mathrm{C}_{2}$. However, overexpression of McaS has been shown to promote motility (Thomason et al. 2012), arguing that the Hfq-dependent positive regulation overrides the negative, CsrA-dependent regulation. In addition, the high abundance of CsrB and CsrC in late exponential phase possibly limits the impact of McaS on CsrA and favors the Hfq-associated base-pairing activity of McaS on other mRNAs. Likewise, by regulating both CsgD (through Hfq) and PgaA (through CsrA), McaS would repress one type of biofilm while activating another. Jørgensen et al. (2013) tentatively explain this with the different growth conditions at which these biofilms form, but such additional layers of control by temperature or environmental factors remain to be tested.

\section{How many more CsrA decoys?}

On more molecular issues, how inclusive or exclusive is the association of McaS with $\mathrm{Hfq}$ versus CsrA? The investigators show that a McaS/Hfq/CsrA ternary complex can form in vitro. If this complex also forms in vivo, perhaps McaS could direct the translational repressor CsrA to specific target mRNAs, similar to the proposed recruitment of RNase $\mathrm{E}$ through a tripartite complex with Hfq and sRNA (Morita et al. 2005). Nonetheless, how does the presence of Hfq impact McaS association with CsrA in vivo? Laudably, Jørgensen et al. (2013) also determined the intracellular concentrations of McaS as well as of CsrB and CsrC, showing that in late stationary phase, the normally lowly abundant McaS sRNA becomes by far the dominant of the three species. However, since both CsrB and CsrC have far more binding sites and higher affinity for CsrA, when does McaS gets a chance to become the dominant regulator? While an attempt to model these events was far beyond the scope of the current study, addressing this two-protein-three-sRNA problem may tell us much about robustness and switch behavior in RNA-based networks. Also, can we be sure that there are no additional CsrB-like sRNAs amongst the known Hfq binders? Interestingly, McaS seems restricted to the genera of Escherichia and Shigella (Jørgensen et al. 2012; Thomason et al. 2012). In contrast, CsgD-controlled biofilm formation is also an important trait in Salmonella, a close pathogenic sibling of E. coli, and again, both CsrA and Hfq are involved (Jonas et al. 2010; Monteiro et al. 2012). This raises the question of whether Salmonella uses other sRNAs with functions analogous to McaS to control biofilm formation in a CsrA-dependent fashion.

Beyond enteric species, the human lung pathogen Pseudomonas aeruginosa possesses the CsrA homolog RsmA, whose activity is regulated by multiple sRNAs, to again, regulate motility, biofilm formation, and virulence in this organism (Lapouge et al. 2008; Brencic and Lory 2009). One of the decoy sRNAs in question is RsmY, which not only interacts with RsmA, but also associates 
with Hfq to gain stability (Sonnleitner et al. 2006). It may now be worthwhile to test whether RsmY also has Hfqdependent targets. Moreover, Pseudomonas species contain an RNA-based system for carbon catabolite repression that operates by a mode analogous to CsrA and sRNAs (Sonnleitner et al. 2009). Here, the translational repressor Crc recognizes CACACA motifs in mRNAs and is modulated by a sRNA decoy that contains multiple copies of that sequence. Does Hfq bind any of these sRNAs, and, if so, do the latter have direct mRNA targets, too?

\section{A new mode of mRNA activation by sRNAs}

The study by Jørgensen et al. (2013) on McaS adds another intriguing example of unusual and unexpected forms of gene activation at the post-transcriptional level. It reveals how CsrA, which for a long time was seen as only a repressor, acts as a positive regulator through an indirect mode of translational derepression. Of note, recent work from the Romeo and Babitzke groups (Yakhnin et al. 2013) has shown that CsrA can even act as a direct mRNA activator by masking a crucial RNase $\mathrm{E}$ site in the flhDC mRNA. By an analogous mechanism of competition with RNase E activity, the Hfq-dependent SgrS sRNA acts as a post-transcriptional activator of one of its targets through mRNA stabilization by direct base-pairing (Papenfort et al. 2013). With respect to the function of $\mathrm{McaS}$ as an antagonist, other recent unexpected findings of positive regulation have also turned out to involve sRNAs and decoy mechanisms (Fig. 2). These include the derepression of chitoporin mRNA translation by an RNA decoy that stems from a functionally related operon mRNA (Figueroa-Bossi et al. 2009; Rasmussen et al. 2009) and the GlmYZ sRNA cascade in which GlmY prevents, by molecular mimicry, the RNase E recruitment factor RapZ from targeting GlmZ so the latter can accumulate and activate gene expression (Gopel et al. 2013). Gene activation by sRNAs has traditionally focused on an antiantisense mechanism whereby the base-pairing of a sRNA disrupts unfavorable structures in the $5^{\prime}$ region of its target mRNA to promote translation (Frohlich and Vogel 2009; Soper et al. 2010), as McaS does with the flhDC mRNA (Thomason et al. 2012). Clearly, the above examples suggest that we have yet to discover the full repertoire of how sRNAs function as post-transcriptional activators of gene expression.

\section{A need for RNA-protein interaction maps in bacteria}

If a last question may be permitted: Could there have been a shortcut to predicting the second life of the Hfqdependent McaS sRNA as a CsrA antagonist? The sRNA itself was discovered as IS061 a decade ago (Chen et al. 2002) but failed to be identified in a recent deep sequencing-based analysis of CsrA-bound transcripts (Edwards et al. 2011), perhaps owing to a lack of annotation or sequencing depth or both. One would thus argue that to predict post-transcriptional circuits in bacteria, the generation of high-resolution RNA-protein interaction maps for abundant global players such as CsrA and Hfq and nucleases such as RNase E would be highly beneficial. Such systematic cataloging has begun to revolutionize our understanding of the scope and importance of RNAprotein interactions in eukaryotes. Using in vivo crosslinking and RNA deep sequencing, the RNA ligands of an increasing number of new RNA-binding proteins have been identified on a global scale; conversely, new RNAbinding proteins are now being systematically searched for in many eukaryotic model systems (Ascano et al. 2013).

The recent years have witnessed plenty of serendipitous discoveries of new RNA-binding proteins in bacteria, too. Examples include the E. coli RapZ protein that

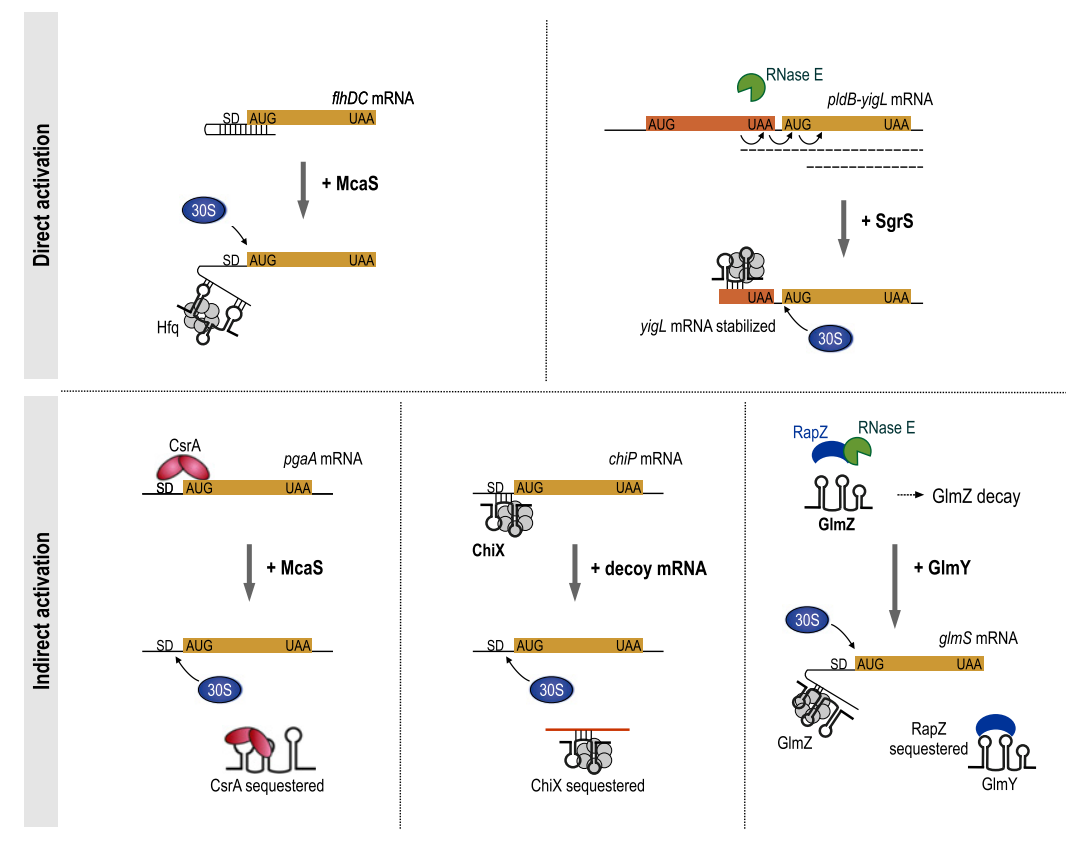

Figure 2. Mechanisms by which sRNAs directly or indirectly exert positive mRNA regulation. Direct activation: (Top left) Binding of McaS sRNA to the flhDC mRNA counteracts the formation of an intramolecular fold-back structure and so promotes translation. (Top right) Activation of YigL synthesis by direct mRNA stabilization. The SgrS sRNA base pairs with the pldByigL mRNA and masks an RNase E cleavage site, thereby stabilizing a decay intermediate that contains the yigL reading frame. Indirect activation: (Bottom left) Repression of PgaA synthesis through binding of CsrA to the pgaA mRNA is counteracted by McaS-mediated sequestration of CsrA. (Bottom middle) Negative regulation of chiP mRNA by ChiX sRNA is counteracted by titration of ChiX through a decoy RNA from the chitobiose operon. (Bottom right) GlmZ is targeted for RNase E-dependent degradation by the adaptor protein RapZ. Sequestration of RapZ protein (an adapter for RNase E) by GlmY sRNA protects the related GlmZ sRNA from RapZ-mediated degradation so that GlmZ accumulates and activates translation of $g \operatorname{lm} S$ mRNA. For references, see the text. 
recruits RNase E for specific degradation of the GlmZ sRNA (Gopel et al. 2013); the translational repressor protein Crc in $P$. aeruginosa, which is antagonized by $\mathrm{CrcZ}$ and other sRNAs (Sonnleitner et al. 2009); the cytoskeletal protein RodZ, which may act on virulence mRNAs in Shigella sonnei (Mitobe et al. 2011); bacterial orthologs of autoantigen Ro that bind noncoding RNAs in various species (Chen et al. 2013); and, last not but least, CsrD, an RNA-binding protein that targets CsrB and CsrC for degradation by RNase E (Suzuki et al. 2006). The present findings by Jørgensen et al. (2013) of an unexpected protein partner of McaS should encourage us to embark on a systematic cataloging of RNA-protein interactions in bacteria, too.

\section{Acknowledgments}

We thank Stan Gorski for reading the manuscript, and Kathrin Fröhlich for help with the art work. J.V. is supported by funds from Deutschen Forschungsgemeinschaft (DFG), Bundesministerien für Bildung und Forschung (BMBF), and the Bavarian BioSysNet program. E.H. is supported by an EMBO long-term fellowship.

\section{References}

Ascano M, Gerstberger S, Tuschl T. 2013. Multi-disciplinary methods to define RNA-protein interactions and regulatory networks. Curr Opin Genet Dev 23: 20-28.

Baker CS, Eory LA, Yakhnin H, Mercante J, Romeo T, Babitzke P. 2007. CsrA inhibits translation initiation of Escherichia coli hfq by binding to a single site overlapping the ShineDalgarno sequence. J Bacteriol 189: 5472-5481.

Beisel CL, Updegrove TB, Janson BJ, Storz G. 2012. Multiple factors dictate target selection by Hfq-binding small RNAs. ЕМВО I 31: 1961-1974.

Brencic A, Lory S. 2009. Determination of the regulon and identification of novel mRNA targets of Pseudomonas aeruginosa RsmA. Mol Microbiol 72: 612-632.

Chao Y, Papenfort K, Reinhardt R, Sharma CM, Vogel J. 2012. An atlas of Hfq-bound transcripts reveals $3^{\prime}$ UTRs as a genomic reservoir of regulatory small RNAs. EMBO $J$ 31: 4005-4019.

Chen S, Lesnik EA, Hall TA, Sampath R, Griffey RH, Ecker DJ, Blyn LB. 2002. A bioinformatics based approach to discover small RNA genes in the Escherichia coli genome. Biosystems 65: 157-177.

Chen X, Taylor DW, Fowler CC, Galan JE, Wang HW, Wolin SL. 2013. An RNA degradation machine sculpted by Ro autoantigen and noncoding RNA. Cell 153: 166-177.

Coornaert A, Chiaruttini C, Springer M, Guillier M. 2013. Posttranscriptional control of the Escherichia coli PhoQ-PhoP two-component system by multiple sRNAs involves a novel pairing region of GcvB. PLoS Genet 9: e1003156.

De Lay N, Gottesman S. 2012. A complex network of small noncoding RNAs regulate motility in Escherichia coli. Mol Microbiol 86: 524-538.

Desnoyers G, Masse E. 2012. Noncanonical repression of translation initiation through small RNA recruitment of the RNA chaperone Hfq. Genes Dev 26: 726-739.

Edwards AN, Patterson-Fortin LM, Vakulskas CA, Mercante JW, Potrykus K, Vinella D, Camacho MI, Fields JA, Thompson SA, Georgellis D, et al. 2011. Circuitry linking the Csr and stringent response global regulatory systems. Mol Microbiol 80: 1561-1580.
Figueroa-Bossi N, Valentini M, Malleret L, Fiorini F, Bossi L. 2009. Caught at its own game: Regulatory small RNA inactivated by an inducible transcript mimicking its target. Genes Dev 23: 2004-2015.

Flemming HC, Wingender J. 2010. The biofilm matrix. Nat Rev Microbiol 8: 623-633.

Frohlich KS, Vogel J. 2009. Activation of gene expression by small RNA. Curr Opin Microbiol 12: 674-682.

Gogol EB, Rhodius VA, Papenfort K, Vogel J, Gross CA. 2011. Small RNAs endow a transcriptional activator with essential repressor functions for single-tier control of a global stress regulon. Proc Natl Acad Sci 108: 12875-12880.

Gopel Y, Papenfort K, Reichenbach B, Vogel J, Gorke B. 2013. Targeted decay of a regulatory small RNA by an adaptor protein for RNase $\mathrm{E}$ and counteraction by an anti-adaptor RNA. Genes \& Dev 27: 552-564.

Heroven AK, Bohme K, Dersch P. 2012. The Csr/Rsm system of Yersinia and related pathogens: A post-transcriptional strategy for managing virulence. RNA Biol 9: 379-391.

Holmqvist E, Reimegård J, Sterk M, Grantcharova N, Römling U, Wagner EGH. 2010. Two antisense RNAs target the transcriptional regulator $\mathrm{CsgD}$ to inhibit curli synthesis. EMBO I 29: 1840-1850.

Holmqvist E, Reimegård J, Wagner EGH. 2013. Massive functional mapping of a $5^{\prime}$ UTR by saturation mutagenesis, phenotypic sorting and deep sequencing. Nucleic Acids Res doi: $10.1093 /$ nar/gkt267.

Jonas K, Edwards AN, Simm R, Romeo T, Römling U, Melefors O. 2008. The RNA binding protein CsrA controls cyclic diGMP metabolism by directly regulating the expression of GGDEF proteins. Mol Microbiol 70: 236-257.

Jonas K, Edwards AN, Ahmad I, Romeo T, Römling U, Melefors O. 2010. Complex regulatory network encompassing the Csr, c-di-GMP and motility systems of Salmonella typhimurium. Environ Microbiol 12: 524-540.

Jørgensen MG, Nielsen JS, Boysen A, Franch T, Møller-Jensen J, Valentin-Hansen P. 2012. Small regulatory RNAs control the multi-cellular adhesive lifestyle of Escherichia coli. Mol Microbiol 84: 36-50.

Jørgensen MG, Thomason MK, Havelund J, Valentin-Hansen P, Storz G. 2013. Dual function of the McaS small RNA in controlling biofilm formation. Genes Dev (this issue). doi: 10.1101/gad.214734.113.

Koo JT, Alleyne TM, Schiano CA, Jafari N, Lathem WW. 2011. Global discovery of small RNAs in Yersinia pseudotuberculosis identifies Yersinia-specific small, noncoding RNAs required for virulence. Proc Natl Acad Sci 108: E709-E717.

Lapouge K, Schubert M, Allain FH, Haas D. 2008. Gac/Rsm signal transduction pathway of $\gamma$-proteobacteria: From RNA recognition to regulation of social behaviour. Mol Microbiol 67: 241-253.

Lawhon SD, Frye JG, Suyemoto M, Porwollik S, McClelland M, Altier C. 2003. Global regulation by CsrA in Salmonella typhimurium. Mol Microbiol 48: 1633-1645.

Lenz DH, Miller MB, Zhu J, Kulkarni RV, Bassler BL. 2005. CsrA and three redundant small RNAs regulate quorum sensing in Vibrio cholerae. Mol Microbiol 58: 1186-1202.

Lopez D, Vlamakis H, Kolter R. 2010. Biofilms. Cold Spring Harb Perspect Biol 2: a000398.

Mika F, Busse S, Possling A, Berkholz J, Tschowri N, Sommerfeldt N, Pruteanu M, Hengge R. 2012. Targeting of $\operatorname{csgD}$ by the small regulatory RNA RprA links stationary phase, biofilm formation and cell envelope stress in Escherichia coli. Mol Microbiol 84: 51-65.

Mitobe J, Yanagihara I, Ohnishi K, Yamamoto S, Ohnishi M, Ishihama A, Watanabe H. 2011. RodZ regulates the post- 
transcriptional processing of the Shigella sonnei type III secretion system. EMBO Rep 12: 911-916.

Monteiro C, Papenfort K, Hentrich K, Ahmad I, Le Guyon S, Reimann R, Grantcharova N, Römling U. 2012. Hfq and Hfqdependent small RNAs are major contributors to multicellular development in Salmonella enterica serovar typhimurium. RNA Biol 9: 489-502.

Morita T, Aiba H. 2011. RNase E action at a distance: Degradation of target mRNAs mediated by an Hfq-binding small RNA in bacteria. Genes Dev 25: 294-298.

Morita T, Maki K, Aiba H. 2005. RNase E-based ribonucleoprotein complexes: Mechanical basis of mRNA destabilization mediated by bacterial noncoding RNAs. Genes Dev 19: 2176-2186.

Ogasawara H, Yamada K, Kori A, Yamamoto K, Ishihama A. 2010. Regulation of the Escherichia coli csgD promoter: Interplay between five transcription factors. Microbiology 156: $2470-2483$.

Papenfort K, Sun Y, Miyakoshi M, Vanderpool CK, Vogel J. 2013. Small RNA-mediated activation of sugar phosphatase mRNA regulates glucose homeostasis. Cell 153: 426-437.

Povolotsky TL, Hengge R. 2012. 'Life-style' control networks in Escherichia coli: Signaling by the second messenger c-diGMP. J Biotechnol 160: 10-16.

Rasmussen AA, Johansen J, Nielsen JS, Overgaard M, Kallipolitis B, Valentin-Hansen P. 2009. A conserved small RNA promotes silencing of the outer membrane protein YbfM. Mol Microbiol 72: 566-577.

Rice JB, Balasubramanian D, Vanderpool CK. 2012. Small RNA binding-site multiplicity involved in translational regulation of a polycistronic mRNA. Proc Natl Acad Sci 109: E2691E2698.

Romeo T, Gong M, Liu MY, Brun-Zinkernagel AM. 1993. Identification and molecular characterization of csrA, a pleiotropic gene from Escherichia coli that affects glycogen biosynthesis, gluconeogenesis, cell size, and surface properties. J Bacteriol 175: 4744-4755.

Romeo T, Vakulskas CA, Babitzke P. 2013. Post-transcriptional regulation on a global scale: Form and function of Csr/Rsm systems. Environ Microbiol 15: 313-324.

Sittka A, Lucchini S, Papenfort K, Sharma CM, Rolle K, Binnewies TT, Hinton JC, Vogel J. 2008. Deep sequencing analysis of small noncoding RNA and mRNA targets of the global post-transcriptional regulator, Hfq. PLoS Genet 4: e1000163.

Sonnleitner E, Schuster M, Sorger-Domenigg T, Greenberg EP, Bläsi U. 2006. Hfq-dependent alterations of the transcriptome profile and effects on quorum sensing in Pseudomonas aeruginosa. Mol Microbiol 59: 1542-1558.

Sonnleitner E, Abdou L, Haas D. 2009. Small RNA as global regulator of carbon catabolite repression in Pseudomonas aeruginosa. Proc Natl Acad Sci 106: 21866-21871.

Soper T, Mandin P, Majdalani N, Gottesman S, Woodson SA. 2010. Positive regulation by small RNAs and the role of Hfq. Proc Natl Acad Sci 107: 9602-9607.

Storz G, Vogel J, Wassarman KM. 2011. Regulation by small RNAs in bacteria: Expanding frontiers. Mol Cell 43: 880891.

Suzuki K, Babitzke P, Kushner SR, Romeo T. 2006. Identification of a novel regulatory protein $(\mathrm{CsrD})$ that targets the global regulatory RNAs CsrB and CsrC for degradation by RNase E. Genes Dev 20: 2605-2617.

Thomason MK, Fontaine F, De Lay N, Storz G. 2012. A small RNA that regulates motility and biofilm formation in response to changes in nutrient availability in Escherichia coli. Mol Microbiol 84: 17-35.
Vogel J, Luisi BF. 2011. Hfq and its constellation of RNA. Nat Rev Microbiol 9: 578-589.

Wang X, Preston JF 3rd, Romeo T. 2004. The pgaABCD locus of Escherichia coli promotes the synthesis of a polysaccharide adhesin required for biofilm formation. I Bacteriol 186: $2724-2734$.

Wang X, Dubey AK, Suzuki K, Baker CS, Babitzke P, Romeo T. 2005. CsrA post-transcriptionally represses pgaABCD, responsible for synthesis of a biofilm polysaccharide adhesin of Escherichia coli. Mol Microbiol 56: 1648-1663.

Wei BL, Brun-Zinkernagel AM, Simecka JW, Pruss BM, Babitzke P, Romeo T. 2001. Positive regulation of motility and flhDC expression by the RNA-binding protein CsrA of Escherichia coli. Mol Microbiol 40: 245-256.

Yakhnin AV, Baker CS, Vakulskas CA, Yakhnin H, Berezin I, Romeo T, Babitzke P. 2013. CsrA activates flhDC expression by protecting flhDC mRNA from RNase E-mediated cleavage. Mol Microbiol 87: 851-866.

Zhang A, Wassarman KM, Rosenow C, Tjaden BC, Storz G, Gottesman S. 2003. Global analysis of small RNA and mRNA targets of Hfq. Mol Microbiol 50: 1111-1124.

Zhang A, Schu DI, Tjaden BC, Storz G, Gottesman S. 2013. Mutations in interaction surfaces differentially impact E. coli $\mathrm{Hfq}$ association with small RNAs and their mRNA targets. J Mol Biol doi: 10.1016/j.jmb.2013.01.006. 


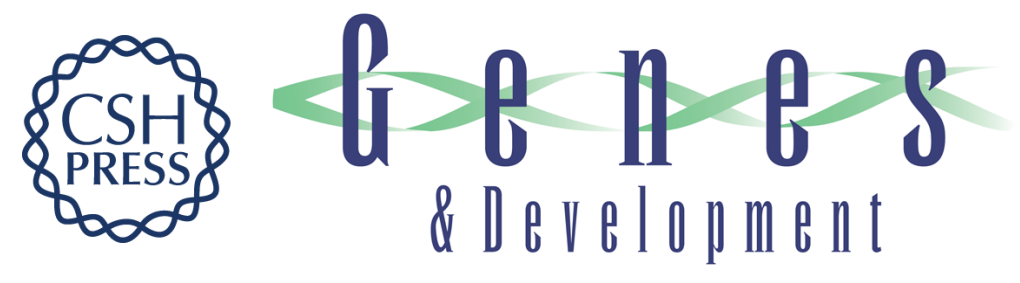

\section{A small RNA serving both the Hfq and CsrA regulons}

Erik Holmqvist and Jörg Vogel

Genes Dev. 2013, 27:

Access the most recent version at doi:10.1101/gad.220178.113
Related Content Dual function of the McaS small RNA in controlling biofilm formation
Mikkel Girke Jørgensen, Maureen K. Thomason, Johannes Havelund, et al.
Genes Dev. May, 2013 27: 1132-1145

References This article cites 51 articles, 15 of which can be accessed free at:

http://genesdev.cshlp.org/content/27/10/1073.full.html\#ref-list-1

Articles cited in:

http://genesdev.cshlp.org/content/27/10/1073.full.html\#related-urls

\section{License}

Email Alerting

Receive free email alerts when new articles cite this article - sign up in the box at the top Service

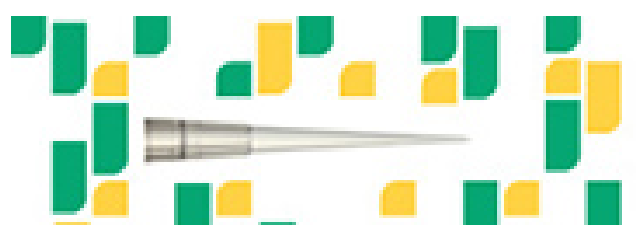

Focused on your science. 